\title{
马衔山茧石矿床茧石裂变径迹年龄的 测定及成矿时代探讨*
}

陈怀录 张良地 吕鸿图

(兰州大学地理系、地质系)

马衔山地区茧石资源丰富. 茧石矿化明显受地层、构造和岩性控制, 具层控矿床特征. 控 矿层位为前震旦系马衔山群第二及第三岩组 $\left(\mathrm{AnZmx}^{2-3}\right)$ 和下震 旦统兴隆山群第四岩组 $\left(Z_{1} \times n^{4}\right)$. 含矿围岩主要为混合岩, 次为混合花岗岩、白云石大理岩和硅质灰岩. 控矿构造为 区域性断层破碎带. 所有茧石矿床均含微量铀. 研究结果表明, 马衔山茧石矿床系在前霞旦 纪海底火山喷发-沉积基础上, 经混合岩化及地下水热液改造而成 ${ }^{[1]}$. 根据围岩性质, 马衔山 层控茧石矿床可进一步分为混合岩型、混合花岗岩型及石灰岩型等类型 ${ }^{[2]}$.

为了探讨马衔山萤石矿床沉积一改造过程及改造成矿时间,本文采用裂变径迹法测定了茧 石矿床中萤石的成矿年龄. 用所得裂变径迹年龄值同围岩已知裂变径迹或同位素年龄进行比 较, 从而得出从矿源层形成直到改造成矿所经历的时间.

\section{一、马衔山群地质年代及同位素和裂变径迹年龄}

广泛发育在马衔山地区的以混合岩为主夹有片麻岩、片岩、粒变岩及大理岩的一套深变质 岩系, 在我国区域地层表上被称为马衔山群, 其地层年代被定为前震旦系 ${ }^{[3]}$. 中国地质科学院 测得马衔山群原岩同位素年龄为 $1719-1886 \mathrm{Ma}^{[4]}$. 甘肃省区测一队委托中国地质科学院用

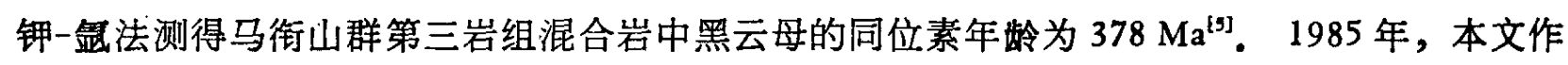
者之一, 用裂变径迹法测得马衔山群混合岩及其它变质岩中石英和角闪石的变质年龄为 $356-366 \mathrm{Ma}$ ，同时测得混合花岗岩中石英的裂变径迹年龄为 $330-341 \mathrm{Ma}^{[6]}$. 上述资料表明， 马衔山群原岩形成于中元古代, 区域变质及混合岩化作用大约完成于古生代泥盆纪末期. 马 衔山混合花岗岩生成时代较混合岩成岩时间为晚,系古生代早石炭世产物。

\section{二、茧石裂变径迹年龄测试过程及结果}

\section{1. 洋品采集、制备与䖵刻分别采取马衔山各萤石矿床 (点) 脉状矿体中有代表性的茧} 石做为待测样品 (表 1 )。

将上述样品切出一新鲜面, 磨平、拋光. 然后将抛光面作为底面, 用环氧树脂固定在载玻 片上,待凉干安固后, 依次用 $\mathrm{M}_{20}, \mathrm{M}_{7}$ 和 $\mathrm{M}_{3,5}$ 金刚砂把营石磨出内表面, 并用氧化铬拋光成一 个光洁透明的光学平面, 接着进行蚀刻. 蚀刻条件为 $98 \% \mathrm{H}_{2} \mathrm{SO}_{4}, 23^{\circ} \mathrm{C}, 12 \mathrm{~min}$. 蚀刻后, 用 自来水、蒸馏水和去离子水清洗, 在无尘环境下晾干.蚀刻后对同一样品作自发径迹密度检查,

本文 1986 年11月12 日收到.

*国家目然科学基金资助项目. 
表 1 裂变经迹年柃样品表

\begin{tabular}{|c|c|c|c|c|}
\hline 样品编号 & 产地 & 矿物名称 & 矿物形态 & 里岩生质 \\
\hline$C_{y}-04$ & 茨泉子 & 䄅色苗石 & 柆状 & 混合花岗岩 \\
\hline $5-10$ & 改河究湾 & 浅绿色萤石 & 立方休 & 混合岩 \\
\hline F-12 & 改河红石崖 & 绿色苖石 & 立方体 & 碳酸蓝岩泥合岩 \\
\hline F -05 & 上梁花石头滩 & 黄色茧石 & 立方体 & 混 合 岩 \\
\hline F $\sim 07$ & 上梁花石头滩 & 黄色茧石 & 块状 & 混 合 岩 \\
\hline$F-13$ & 二 岭 沟 & 㤻色瞢石 & 块状 & 混合花岗岩 \\
\hline$F-15$ & 杨家后沟 & 浅黄色茧石 & 粒状 & 硅质灭岩 \\
\hline
\end{tabular}

结果发现, 在光洁透明的茧石晶体上出现了清晰可辨的长条形自发裂变径迹 (图 1). 然后在 蚀刻和清洗晾干的茧石表面上覆盖一片纯净(含铀量极低) 的聚碳酸脂薄膜 (辽宁朝阳塑料厂 产品), 用透明胶带扎紧, 用高纯铝箔包好, 送九 $\bigcirc$ 二所反应堆中进行辐照, 以金片做中子剂量 监测器. 辐照积分通量为 $3.3 \times 10^{16}$ 中子 $/ \mathrm{cm}^{2}$. 辐照完毕搁置数十天后在薄膜上圈出与茧石晶 体相对应的位置，揭下薄膜进行蚀刻. 蚀刻条件为 $6.25 \mathrm{~mol} / 1$ 的 $\mathrm{NaOH}$ 水溶液, $50^{\circ} \mathrm{C}, 80 \mathrm{~min}$, 清洗后用光学显微镜观察统计茧石上已蚀刻出来的自发裂变径迹密度 $\left(\rho_{s}\right)$ 和薄膜上诱发径迹 密度 $\left(\rho_{i}\right)$.

2. 测试过程我们用生物显微镜 (油浸物镜 $10 \times 100$ ) 和血球计数器对茧石样品进行 自发径迹统计测定. 观察中发现, 茧石中的自发裂变径迹形状主要有两种: 一种是绿色茧石 中常见长条形 (图 1); 另一种是黄色萤石中出现的较粗一些的小虫状 (图 2). 这两种径迹均

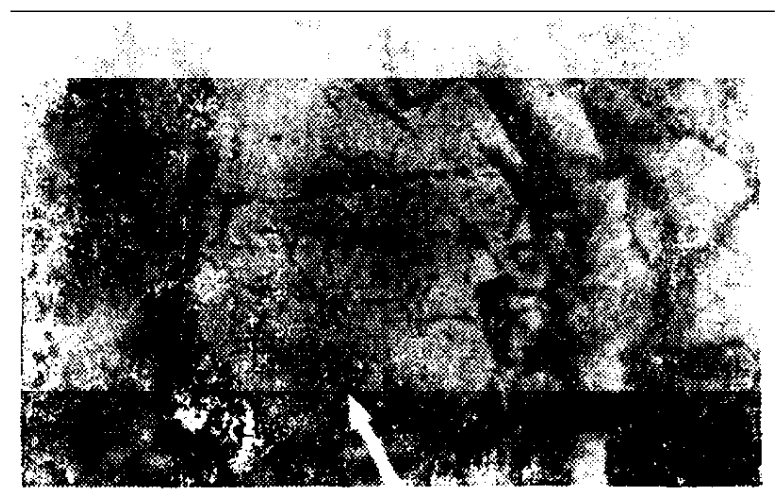

图 1 绿色萤石自发裂变径迹 $(320 x)$

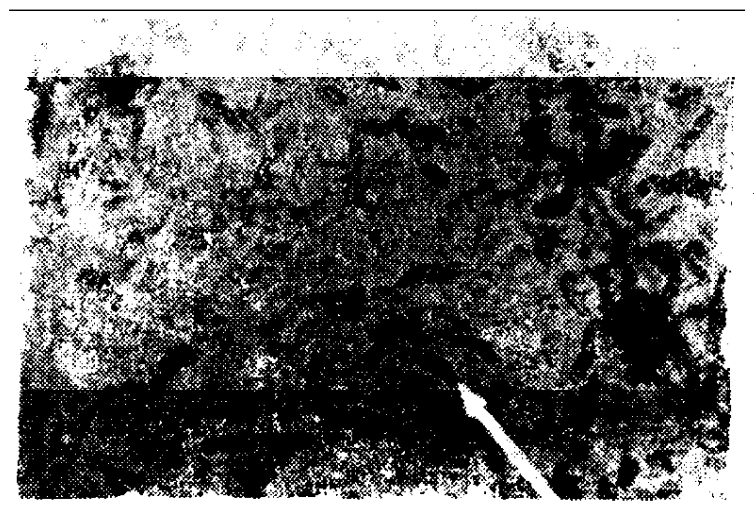

图 2 黄色董石目发裂变经迹 $(320 x)$

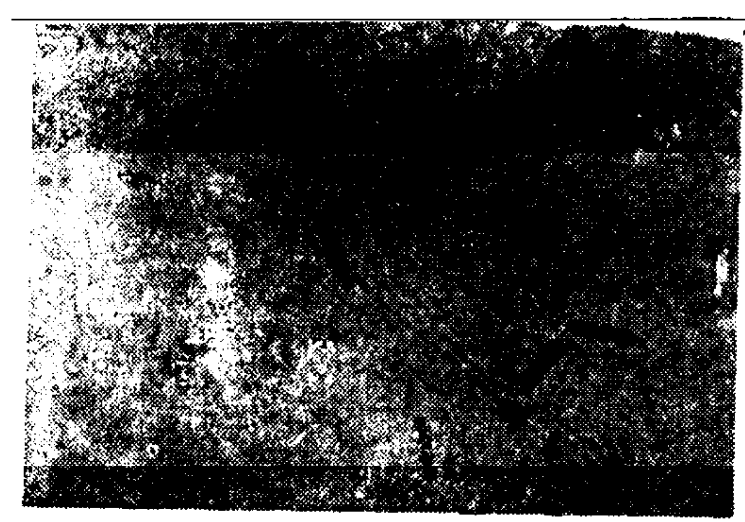

图 3 外探测器诱发裂变径迹 $(320 \times)$ 
易辨认，在显微镜下由两人重复观察统计了自发径迹密度. 薄膜上诱发径迹清晰 (图 3). 用 同样方法统计了诱发径迹密度. 为了确保外探测器与黄石颗粒相印一致，以及所得数据的可 靠性,我们进行了自发径迹和诱发径迹密度验证。其结果表明,两者完全吻合. 即自发裂变径 迹密度高的区域诱发裂变径迹密度也相应增大, 反之亦然。

通过测量统计出自发裂变径迹密度和诱发裂变径迹密度后, 用下列公式编制计算程序,并 采用计算机计算了年代和误差.

$$
T=\frac{1}{\lambda D} \ln \left(1+\frac{\rho_{s}}{2 \rho_{i}} \cdot \frac{\lambda D}{\lambda f} \cdot I \cdot \sigma \cdot \phi \cdot \varepsilon\right),
$$

式中 $T$ 一一矿物生成或受热冷却后的年代; $\lambda D-{ }^{238} U$ 总衰变常数 $\left(1.54 \times 10^{-10} \mathrm{a}^{-1}\right) ; \rho_{s}-$ 自发裂变径迹密度; $\rho_{i}$ 一诱发裂变径迹密度 (外探测器为 $\left.2 \rho_{i}\right) ; \lambda f-{ }^{238} \mathrm{U}$ 的自发裂变衰变 常数 $\left(6.9 \times 10^{-17} \mathrm{a}^{-1}\right) ; I$ 一铀同位素丰度比 $\left({ }^{235} \mathrm{U} /{ }^{238} \mathrm{U}=7.26 \times 10^{-3}\right) ; \sigma-{ }^{235} \mathrm{U}$ 裂变的有 效截面 $\left(562 \times 10^{-24} \mathrm{~cm}^{2}\right) ; \phi$ 一一等效于 $2200 \mathrm{~m} / \mathrm{s}$ 的中子积分通量; $\varepsilon$ 一一外探测器效率 (0.955).

测量计算黄石裂变径迹年龄结果列于表 2 .

表 2 茧石裂变径迹年龄测定结果

\begin{tabular}{|c|c|c|c|c|c|c|c|}
\hline 编 号 & 矿物名称 & $\begin{array}{c}\text { 中子积分通 } \\
\left(\mathrm{n} / \mathrm{cm}^{2}\right)\end{array}$ & $\mid \begin{array}{c}\text { (自发径迹数目 } \\
\text { (条) }\end{array}$ & $\begin{array}{c}\text { 自发径迹密度 } \\
\left(10^{6} / \mathrm{cm}^{2}\right)\end{array}$ & 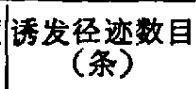 & $\begin{array}{c}\text { 诖发径迹密度 } \\
\left(10^{6} / \mathrm{cm}^{2}\right)\end{array}$ & $\begin{array}{l}\text { 年蛉 } \\
(\mathrm{Ma})\end{array}$ \\
\hline C-04 & 茧石 & $3.3 \times 10^{26}$ & 928 & 6.23 & 4163 & 29.65 & $192.7 \pm 16.4$ \\
\hline F-10 & 同上 & $3.3 \times 10^{16}$ & 1140 & 8.12 & 4577 & 32.60 & $227.8 \pm 18.0$ \\
\hline$F-12$ & 同上 & $3.3 \times 10^{16}$ & 1085 & 7.73 & 4374 & 31.15 & $227.0 \pm 18.0$ \\
\hline$F-05$ & 同上 & $3.3 \times 10^{16}$ & 1283 & 9.14 & 5208 & 37.10 & $225.4 \pm 18.6$ \\
\hline F-07 & 同上 & $3.3 \times 10^{16}$ & 1312 & 9.35 & 5339 & 38.03 & $225.2 \pm 18.6$ \\
\hline F-13 & 同上 & $3.3 \times 10^{26}$ & 320 & 2.28 & 1502 & 10.7 & $195.4 \pm 16.5$ \\
\hline$F-15$ & 同上 & $3.3 \times 10^{16}$ & 217 & 1.55 & 1086 & 7.74 & $183.9 \pm 15.8$ \\
\hline
\end{tabular}

\section{三、马衔山群变质岩体的热历史与茧石成矿时代讨论}

1. 马衔山群变质岩体的热历史研究资料表明,裂变径迹有退火愈合的特性 ${ }^{[7,03}$. 每种 矿物都有其自己的裂变径迹退火温度, 如角闪石在 $630^{\circ} \mathrm{C}$, 加热一小时能使裂变 径迹全部退 火,而方解石只要 $350^{\circ} \mathrm{C}$ (一小时). 由于各种矿物退火的温度不同, 它们的起始计时温度也是 不一样的. 利用同一岩体内各种不同矿物不同裂变径迹计时温度,可以计算岩石的热历史. 例 如,榍石的裂变径迹封闭 (保留) 温度一般确定为 $250^{\circ} \mathrm{C}^{[9]}$ ，锆石为 $175-220^{\circ} \mathrm{C}$, 磷灰石为 90 $-120^{\circ} \mathrm{C}^{[10]}$, 黑云母 $\mathrm{K}-\mathrm{Ar}$ 系统的有效封闭温度一般为 $220 \pm 40^{\circ} \mathrm{C}^{[11]}$. 如果我们把黑云母 $\mathrm{K}-$ $\mathrm{Ar}^{[g]}$ 封闭温度取值为 $250^{\circ} \mathrm{C}$, 角闪石裂变径迹 ${ }^{[6]}$ 封闭温度取值为 $180^{\circ} \mathrm{C}$, 那么, 马衔山群受强烈 区域变质作用的岩体冷却速度应为 $4.12-5.83^{\circ} \mathrm{C} / \mathrm{Ma}$, 即这种冷却过程大约延续了 $17 \mathrm{Ma}$, 大 约在 330-341 Ma 前 ${ }^{63}$, 又有一次混合花岩的侵入。由此可见，马衔山群经受最强裂的区域 变质作用是 $350 \mathrm{Ma}$ 之前的加里东运动和早华力西运动.

2. 蒙石成矿时代 由表 2 测定结果并参阅表 1 地质产状可以看出，马衔山茧石裂变径 
迹年龄分为三组: $183.9 \mathrm{Ma}$ 组 (石灰岩型茧石矿床)；192.7-195.4Ma 组(混合花岗岩型茧石 矿床)；225.2-227.8Ma (混合岩型茧石矿床)。即石灰岩型薥石矿床成矿年龄值 最小（最终 改造成矿的时间最晚)，混合花岗岩型茧石矿床成矿年龄次之；而混合岩型茧石矿床成矿年龄 值最大(最终改造成矿的时间最早)。这与马衔山各类萤石矿床成矿地质条件的差异性 ${ }^{[2]}$ 相吻 合.

产于混合岩中的茧石矿床，是马衔山地区最重要的一类茧石矿床资源。由围岩(混合岩) 及茧石裂变径迹年龄可知,改造成矿作用主要发生在加里东期和华力西期,改造成矿最终完成 于华力西末期 (即黄石裂变径迹年龄为 225.2-227.8Ma). 同矿源层形成时代相比, 改造成矿 经历了 1494-1658Ma 的漫长历程. 与原岩混合岩化成岩时代也有 131-139Ma 时差.

混合花岗岩型茧石矿床,瞢石年龄为 192.7-195.4Ma，即茧石改造成矿完成于印支期。这 类矿床较混合岩型茧石矿床改造成矿时间之所以为晚, 是因为混合花岗岩系混合岩化和花岗 岩化作用最终阶段产物所致. 上已述及,混合花岗岩裂变径迹年龄为 $330-341 \mathrm{Ma}$, 比混合岩 形成时间约晚 25-26Ma。岩体形成后, 又经历了 137-146Ma 的含矿热液改造, 于印支期才 最终成矿. 如果考虑矿源层形成时间, 那么从矿源层 $\rightarrow$ 混合岩化 $\rightarrow$ 花岗岩化 $\rightarrow$ 最终改造成 矿,历时约 1526-1691Ma。

石灰岩型萤石矿床,薥石年龄为 $183.9 \mathrm{Ma}$ ，应为印支末期的产物. 这类萤石矿床由于来自 基底(马衔山群)的含矿热液,异地充填和交代时代较新的石灰岩而成,故改造成矿时间完成的 最晚。

致谢: 地质系唐片室刘文庭工程师帮助制片，九 $\bigcirc$ 二所李玉诖同志邦助样品辐照，在此致以谢意。

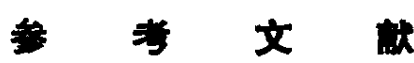

[1]张良加、辚伓录、吕鸡图,兰州大学学报 (特发表).

[2]张良相、吕鸿图、陈伓录，西北开发探索文集(第二集),四川科技出版社(待出版).

[3] 甘杰省区一队, 中华人民共和国地质图说明书 (1/20万,定西幅)，1965.

[4] 中国地质科学院,中华人民共和国地质图 (1/400 万), 地图出版社, 1976 .

[5] 甘当省区溂队, 中华人民共和国地质图说明书 (1/20 万), 监夏愊, 1965.

[6] 傅学明、陈吥录、郑国东等, 兰州大学学报, 21(1985), 1: 74-78.

[7] 刘顺生、张特等,裂变径迹年数测定方法、技术和应用,地质出版社, 1984.

[8]陈样高、张忠本,科学通报, 28(1983), 6: 357-359.

[9] Wagner, G. A., Fission track dating of apatites, Eorth Plonet, Sci. Leth, 14(1968), 411.

[10] Leadow, A. G. and Pucldy, I. R., Pisa, 10-13 September, Bigazzi, G. ed (abstract), 1980

[11]中国科学浣地质研究所钾一年年龄组,地质科学, 1979, 1：13-21. 